\title{
RELATORIO DO ANNO 1924
}

Cumprindo o disposto na letra i) do artigo 114 do Decreto n. 11.530, de 18 de Março de 1915, e do n. XVII do art. 9. ${ }^{\circ}$ do Regimento Interno desta Faculdade, passo a fazer o relatorio minucioso de tudo quanto occorreu, neste estabelecimento, a respeito da ordem, disciplina, serviço militar, observancia das leis e do orçamento do anno lectivo findo de 1924.

Abertura dos trabalhos. - Na forma do disposto no art. 74 do Decreto n. ${ }^{\circ} 11.530$, de 18 de Março de 1915 e do art. 143 do Regimento Interno desta Faculdade, os trabalhos deste Instituto de ensino abriram-se no dia 3 de Março, por terem sido feriados os dois dias anteriores, celebrando a Congregação dos Professores, nesse diá, a sua pimeira reunião.

Presença de Professores. - Na primeira reunião da Congregação, realizada a 3 de Março, foi verificado que se achavam promptos para os cursos, os Professores Drs. Uladislau Herculano de Freitas, Antonio Amancio Pereira de Carvalho, Antonio Januario Pinto Ferraz, Manoel Pedro Villaboim, José Ulpiano Pinto de Souza, Candido Nazianzeno Nogueira da Motta, Reynaldo Porchat, Frederico Vergueiro Steidel, João Braz de Oliveira Arruda, Estevam de Araujo Almeida, Manoel Pacheco Prates, Theophilo Benedicto de Souza Carvalho, José Joaquim Cardoso de Mello Neto, José Manoel de Azevedo Marques, Francisco Antonio de Almeida Morato e Octavio Mendes, e os substitutos na regencia de cadeiras: Braz de Sousa Arruda, além dos substi- 
tutos que não regiam cadeiras: Drs. Spencer Vampré, José Augusto Cesar, Raphael Corrêa de Sampaio e José de Alcantara Machado d'Oliveira.

Exame vestibular. - Na forma do disposto o art. 62 do Regimento Interno, a inscripção para o exame vestibular, instituido pelo art. 77, letra $c$ ) do Decreto n. ${ }^{\circ} 11.530$, de 1915, para a matricula no curso desta Faculdade, aberta a 2 de Janeiro de 1924 e encerrada a 12 do mesmo mez, e, reaberta a 7 de Março, de conformidade com o disposto no art. 2. ' do Decreto n. 4.228; de 30 de Dezembro de 1921, e a resolução do Conselho Superior do Ensino, tomada a sessão a 23 de Novembro de 1922, foi encerrada a 15 do mesmo mez, tendo ella concorrido setenta e cinco candidatos (75), sendo na $1 .^{\text {a }}$ epoca vinte quatro (24) e $2 .^{a}$ cincoenta e um (51). O exame iniciou-se com a prova escripta, para os inscriptos na 1. ${ }^{\mathrm{a}}$ epoca, no dia 28 de Janeiro, tendo terminado no dia 30 desse mesmo mez, e, para os inscriptos na 2. ${ }^{a}$ epoca, no dia 24 de Março. tendo terminado no dia $1 .^{\circ}$ de Abril seguinte. 0 resultado desse julgamento foi o seguinte: em Janeiro, approvados 15 , inhablitados na prova escripta 8 e reprovado 1 , total 24; e, em Março: approvados 30, inhabilitados na prova escripta 16 e reprovados 5, total 51. Annexo respectivo).

A commissão julgadora desse exame foi constituida, nas duas epocas, dos Drs. Frederico Vergueiro Steidel, Theophilo Benedicto de Souza Carvalho, Francisco Antonio de Almeida Morato, Manoel Pacheco Prates, Spencer Vampré e Raphael Corrêa de Sampaio, este em substituição ao Dr. José Augusto Cesar, que participou não poder comparecer.

Horario das aulas. - Pela Congregação dos Professores, em reunião realizada a 3 de Março, foi adoptado o Horario das aulas, constantes do annexo respectivo. 
Programmas de ensino. - Adoptados pelos Professores das cadeiras do curso, foi nomeada uma commissão composta dos Dr. Frederico Vergueiro Steidel, Manoel Pacheco Prates e Francisẹo Antonio de Almeida Morato, a qual formulou o seu parecer, opinando pela sua aprovação, parecer esse que foi approvado na mesma sessão de 3 de Março. Os programmas foram impressos e postos á venda na Thesouraria da Faculdade.

Designação de Professores. - No correr do anno lectivo findo, foram designados: o Dr. Spencer Vampré, substituto da $1 .^{a}$ secção, para reger a $3 .^{a}$ cadeira do 1 . anno, em substituição ao Dr. Reynaldo Porchat e a $4 .^{\text {a }}$ cadeira do 5. anno, em substituição ao Dr. Manoel Pedro Villaboim; o Dr. Braz de Sousa Arruda, substituto da 2." secção, para reger a $2 .^{: ~ c a d e i r a ~ d o ~} 10^{\circ}$ anno, em substituição ao Dr. Uladislau Herculano de Freitas; o Dr. José Augusto Cesar, substituto da $3 .^{a}$ secção, para reger a $3 .^{a}$ cadeira do 4." anno, em substituição ao Dr. José Ulpiano Pinto de Souza, e o Dr. Raphael Corrêa de Sampaio, substituto da 4. ${ }^{a}$ secção, para reger a $2 .^{a}$ cadeira do $3 .^{\circ}$ anno, em substituição ao Dr. Luiz Barbosa da Gama Cerqueira.

Inscripção para exame da 2. ${ }^{\mathrm{a}}$ epoca. - - Para os exames da 2." epoca, inscreveram-se 64 alumnos, sendo: no 1." anno 9 , no 2 . 20 , no $3 .^{\circ} 14$, no $4 .^{\circ} 15$ e no $5 .^{\circ} 6.0$ resultado desses exames consta do annexo respectivo.

Inscripção de matricula. - Matricularam-se nos cinco annos do curso 293 alumnos, sendo no $1 .^{\circ}$ anno 52 , no $2 .^{\circ} 62$, dos quaes um do sexo feminino, no $3 .^{\circ} 75$, dos quaes tres do sexo feminino, no 4. 55, dos quaes um do sexo feminino, e no $5 .^{\circ} 49$.

Transferencia de matricula. - Durante o periodo das ferias, tres alumnos requereram guia de transferencia, sendo um do 2..$^{\circ}$ anno, para a Faculdade de Direito da 
Universidade do Rio de Janeiro, e dois do $5 .^{\circ}$ anno, sendo um para a Faculdade de Direito do Recife e o outro para a Faculdade de Direito da Universidade do Rio de Janeiro.

Licenças. - Durante o anno lectivo findo, estiveram no gozo de licença: o Dr. José Ulpiano Pinto de Souza, cathedratico da $3 .^{2}$ cadeira do $4 .^{\circ}$ anno, de 1 . de Julho a 3 de Agosto; o Dr. Reynaldo Porchat, cathedratico da $3 .^{a}$ cadeira do $1 .^{\circ}$ anno, de 6 de Outubro a 3 de Novembro, e o Dr. Luiz Barbosa da Gama Cerqueira, cathedratico da $2 .^{a}$ cadeira do $3 .^{\circ}$ anno, de 2 a 21 de Dezembro.

Serviço publico. - Durante o anno findo, estiveram ausentes desta Faculdade, por motivo de serviçó publico: o Dr. Uladislau Herculano de Freitas, Director, como representante desta Faculdade, no Conselho Superior do Ensino, de $1 .^{\circ}$ de Fevereiro a 8 de Março e de 15 de Abril a 31 de Dezembro, com assento no Congresso Nacional, como Deputado eleito pelo Estado de S. Paulo; o Dr. Manoel Pedro Villaboim, de 15 de Abril a 31 de Dezembro, com assento no Congresso Nacional, como Deputado eleito pelo Estado de S. Paulo, e o Dr. Reynaldo Porchat, como representante desta Faculdade, no Conselho Superior do Ensino, de 1. de Fevereiro a 8 de Março.

Substituições. - No correr do anno lectivo findo, o Dr. Antonio Amancio Pereira de Carvalho, cathedratico mais antigo e vice-Director, na forma da lei, substituiu ao Dr. Uladislau Herculano de Freitas, no exercicio do cargo de Director, de $1 .^{\circ}$ de Fevereiro a 8 de Março, e. de 15 de Abril a 31 de Dezembro; o Dr. Spencer Vampré, substituto da $1 .^{a}$ secção, de 6 de Outubro a 3 de Novembro, regeu a $3 .^{a}$ cadeira do $1 .^{\circ}$ anno, em substituição ao Dr. Reynaldo Porchat, e de 15 de Abril a 31 de Dezembro, regeu tambem a $4 .^{a}$ cadeira do $6 .^{\circ}$ anno, em substituição ao Dr. Manoel Pedro Villaboim; o Dr. Braz 
de Sousa Arruda, substituto da 2. ${ }^{\mathrm{a}}$ secção, de 15 de Abril a 31 de Dezembro, regeu a $2 .^{a}$ cadeira do $1 .^{\circ}$ anno, em substituição ao Dr. Uladislau Herculano de Freitas; o Dr. José Augusto Cesar, substituto da $3 .^{a}$ secção, de 4 de Julho a 3 de Agosto, regeu a $3 .^{a}$ cadeira do $4 .^{\circ}$ anno, em substituição ao Dr. José Ulpiano Pinto de Souza, e o Dr. Raphael Corrêa de Sampaio, substituto da $4 .^{a}$ secção, de 2 a 23 de Dezembro, regeu a $2 .^{a}$ cadeira do $3 .^{\circ}$ anno, em substituição ao Dr. Luiz Barbosa da Gama Cerqueira.

Inscripção para exames da primeira epoca. - Para os exames da $1 .^{a}$ epoca, inscreveram-se 256 alumnos. sendo: no $1 .^{\circ}$ anno 43 , no $2 .^{\circ} 59$, no $3 .^{\circ} 62$, no $4 .^{\circ} 45$ e no $5 .^{\circ} 47$. O resultado desses exames consta do annexo respectivo.

Collação de grau. - Durante o anno findo, foi col. lado o grau de Bacharel em Sciencias Juridicas e Sociaes a 50 Bacharelandos, dos quaes cinco concluiram o curso na $2 .^{a}$ epoca de 1923, e os restantes quarenta e cinco o concluiram na primeira epoca do anno lectivo findo.

Desses cincoenta (50) Bachareis, são naturaes do Estado de S. Paulo, 42; de Minas Geraes, 5; da Bahia, 2 da Cidade do Rio de Janeiro (annexo rdspectivo)

Cartas de Bacharel. - Durante o anno findo, foram expedidas 90 (noventa) Cartas de Bacharel a egual numero de Bacharelandos formados por esta Faculdade, sendo um somente em Sciencias Juridicas, que concluiu o curso em 1895.

Desses noventa (90) Bachareis, são naturaes: do Estado de S. Paulo, 71; do de Minas Geraes, 5; do de Rio de Janeiro, 3; da Cidade do Rio de Janeiro, 2; do Estado de Sergipe, 2; do de Pernambuco, 2; do da Bahia, 2; do de Rio Grande do Norte, 1; do de Paraná, 1 e do Rio Grande do Sul, 1. (Annexo respectivo).

Serviço Militar. - De conformidade com a informação prestada pelo respectivo Instructor Militar, du- 
rante o anno findo, frequentaram a instruç̧ão militar apenas oito (8) alumnos desta Faculdade, tendo prestado exame somente tres (3), que foram approvados.

Sessões da Congregação. - No correr do anno findo, a Congregação dos Professores celebrou cinco (5) sessóeș, nas quaes foram tratados diversos assumptos.

Procedimento dos alumnos. - $\mathrm{O}$ procedimento dos alumnos, no decorrer do anno findo, foi bom, nada tendo occorrido digno de menção.

Bibliotheca. - A Bibliotheca desta Faculdade foi frequentada, durante $\mathrm{o}$ anno, por 5.022 pessoas, que consultaram 1.915 obras, em 3.490 volumes, sendo em Portuguez, 1.291; em Francez, 410; em Italiano, 86; em Latim, 63; em Hespanhol, 47; e em Inglez, 18; estando no numero dos consulentes incluidas 2.108 pessôas, que leram jornaes e revistas. (Annexo respectivo).

Os empregados da Bibliotheca bem cumpriram os seus deveres.

Thesouraria. - $\mathrm{O}$ balanço demonstrativo da Thesouraria desta Faculdade, constante do annexo respectivo, fechado a 31 de Dezembro de 1924, accusa que, da Receita e Despeza, ha um saldo de setecentos e quarenta e dois contos quinhentos e cincoenta e sete mil seiscentos réis (742:557\$600), assim distribuidos: no Banco do Commercio e Industria 47:000\$200 (quarenta e sete contos e duzentos réis), no Banco do Brasil 9:557\$400 (nove contos quinhentos e cincoenta e sete mil quatrocentos réis), $\mathrm{e}$ 686:000\$000 (seiscentos e oitenta e seis contos de réis) importancia de 686 (seiscentos e oitenta e seis) apolices da União, do valor de um conto de réis, cada uma, e ao juro de cinco por cento $(5 \%)$ ao anno.

O saldo apurado em 1923 foi de 756:394\$400 (setecentos e cincoenta e seis contos trezentos e noventa e quatro 
mil quatrocentos réis), havendo, portanto, uma differença a menos, de 13:836\$800 (treze contos oitocentos e trinta e seis mil oitocentos réis), devido ao numero de alumnos, que, no anno findo, soffreu diminuição.

0 Thesoureiro bem cumpriu os seus deveres.

Secretaria. - Os serviços da Secretaria estiveram sempre em dia, tendo os empregados bem cumprido os seus deveres.

Secretaria da Faculdade de Direito de São Paulo, em 26 de Janeiro de 1925.
O Director:

Dr. Uladislau Herculano de Freitas. 